\title{
Dopaminergic Signaling in the Cochlea: Receptor Expression Patterns and Deletion Phenotypes
}

\author{
Stéphane F. Maison, ${ }^{1,2,3}$ Xiao-Ping Liu, ${ }^{2,3}$ Ruth Anne Eatock, ${ }^{1,2,3}$ David R. Sibley, ${ }^{4}$ David K. Grandy, ${ }^{5}$ \\ and M. Charles Liberman ${ }^{1,2,3}$ \\ ${ }^{1}$ Department of Otology and Laryngology, Harvard Medical School, Boston, Massachusetts 02114, ${ }^{2}$ Eaton-Peabody Laboratory, Massachusetts Eye \& Ear \\ Infirmary, Boston, Massachusetts 02114, ${ }^{3}$ Program in Speech and Hearing Biosciences and Technology, Harvard-MIT, Cambridge, Massachusetts 02139, \\ ${ }^{4}$ Molecular Neuropharmacology Section, National Institute of Neurological Disorders and Stroke, Bethesda, Maryland 20892, and ${ }^{5}$ Department of \\ Physiology and Pharmacology, Oregon Health \& Science University, Portland, Oregon 97239
}

Pharmacological studies suggest that dopamine release from lateral olivocochlear efferent neurons suppresses spontaneous and soundevoked activity in cochlear nerve fibers and helps control noise-induced excitotoxicity; however, the literature on cochlear expression and localization of dopamine receptors is contradictory. To better characterize cochlear dopaminergic signaling, we studied receptor localization using immunohistochemistry or reverse transcriptase PCR and assessed histopathology, cochlear responses and olivocochlear function in mice with targeted deletion of each of the five receptor subtypes. In normal ears, D1, D2, and D5 receptors were detected in microdissected immature (postnatal days 10-13) spiral ganglion cells and outer hair cells but not inner hair cells. D4 was detected in spiral ganglion cells only. In whole cochlea samples from adults, transcripts for D1, D2, D4, and D5 were present, whereas D3 mRNA was never detected. D1 and D2 immunolabeling was localized to cochlear nerve fibers, near the first nodes of Ranvier (D2) and in the inner spiral bundle region (D1 and D2) where presynaptic olivocochlear terminals are found. No other receptor labeling was consistent. Cochlear function was normal in D3, D4, and D5 knock-outs. D1 and D2 knock-outs showed slight, but significant enhancement and suppression, respectively, of cochlear responses, both in the neural output [auditory brainstem response (ABR) wave 1] and in outer hair cell function [distortion product otoacoustic emissions (DPOAEs)]. Vulnerability to acoustic injury was significantly increased in D2, D4 and D5 lines: D1 could not be tested, and no differences were seen in D3 mutants, consistent with a lack of receptor expression. The increased vulnerability in D2 knock-outs was seen in DPOAEs, suggesting a role for dopamine in the outer hair cell area. In D4 and D5 knock-outs, the increased noise vulnerability was seen only in ABRs, consistent with a role for dopaminergic signaling in minimizing neural damage.

\section{Introduction}

The neurons and sensory cells of the inner ear are subject to feedback control from the brainstem via the olivocochlear (OC) efferent system (Fig. 1). This system comprises a medial OC (MOC) component of myelinated fibers giving rise to cholinergic synapses on outer hair cells (OHCs) and a lateral OC (LOC) component of unmyelinated fibers projecting to cochlear nerve fibers in the inner hair cell (IHC) area, among other peripheral targets (for review, see Guinan, 2006). The MOC fibers form the effector arm of a sound-evoked inhibitory reflex that performs rapid (within tens of milliseconds) automatic gain-control on the

Received Sept. 6, 2011; revised Oct. 31, 2011; accepted Nov. 5, 2011.

Author contributions: S.F.M., X.-P.L., R.A.E., and M.C.L. designed research;S.F.M., X.P.L., and M.C.L. performed research; D.R.S. and D.K.G. contributed unpublished reagents/analytic tools; S.F.M. and M.C.L. analyzed data; S.F.M. and M.C.L. wrote the paper.

This work was supported by National Institutes of Health Grants R01 DC0188 (M.C.L.), R01 DC02290 (R.A.E.), and P30 DC5029 (M.C.L.). We are indebted to Dr. Malcolm Low for his help in guiding us to sources for DR knock-out lines. We thank Ben Winterroth for setting up the protocol used to amplify messenger RNA from small numbers of cells. The skillful assistance of Leslie Dodds and Constance Miller is gratefully acknowledged.

Correspondence should be addressed to Dr. Stéphane F. Maison, Eaton-Peabody Laboratory, Massachusetts Eye \& Ear Infirmary, 243 Charles Street, Boston, MA 02114-3096. Email: stephane_maison@meei.harvard.edu.

DOI:10.1523/JNEUROSCI.4720-11.2012

Copyright $\odot 2012$ the authors $\quad 0270-6474 / 12 / 320344-12 \$ 15.00 / 0$ mechanical amplifier powered by OHC electromotility. The nAChRs that mediate these MOC effects on OHCs (heteromeric channels composed of $\alpha 9$ and $\alpha 10$ subunits) have been well characterized (Vetter et al., 1999, 2007).

It is not known whether LOC activity can be sound evoked; however, electrical activation results in slow (within tens of seconds) modulation in the excitability of cochlear nerve afferents: either excitation or inhibition depending on the locus of stimulation in the brainstem (Groff and Liberman, 2003). This slow modulation may be important in adjusting the output from the two ears to maintain accuracy in sound localization (Darrow et al., 2006b). Immunohistochemical evidence suggests that the LOC system can be subdivided into cholinergic and dopaminergic components (Jones et al., 1987; Eybalin et al., 1993; Mulders and Robertson, 2004; Darrow et al., 2006a), and dopaminergic signaling may be mediating the LOC's inhibitory effects. There is biochemical evidence that dopamine can be released from neurons by shocking the cochlea (Gáborján et al., 1999), and there is pharmacological evidence that dopamine perfusion decreases spontaneous and sound-evoked activity in the cochlear nerve (Ruel et al., 2001). This dopaminergic inhibition may also be important in minimizing glutamate excitotoxicity at the afferent 


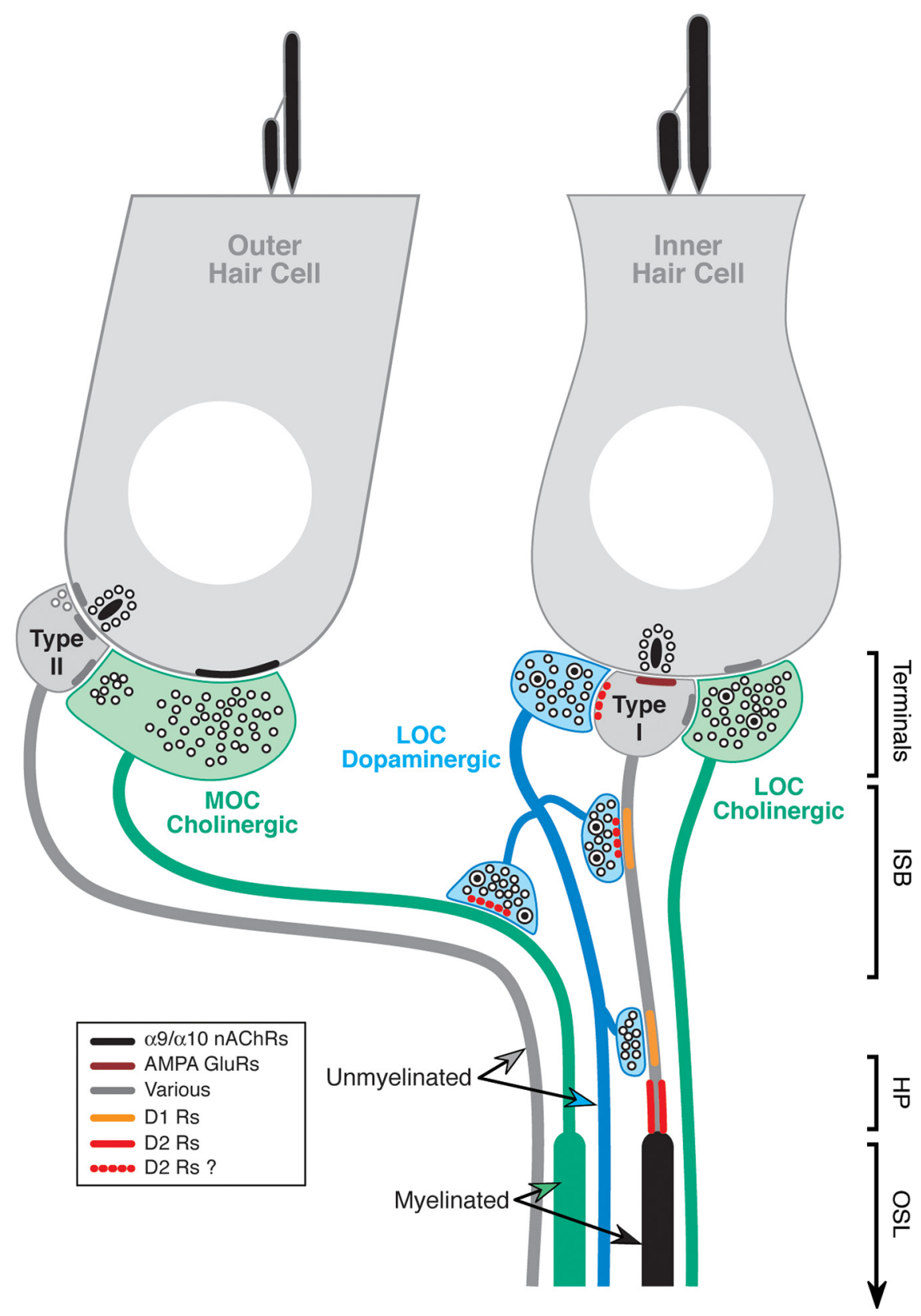

Figure 1. Schematic of the synaptic interactions among hair cells, cochlear nerve afferents, and olivocochlear efferent fibers in the mammalian cochlea. The connections and AMPA receptor localization are known from ultrastructural studies (Liberman, 1980a,b; Matsubara et al., 1996); the nature of the cholinergic receptors on outer hair cells is known from knock-out studies (Vetter et al., 1999, 2007). Dopamine receptor localization (red and orange bars— - see key) is inferred from the D1 and D2 receptor immunohistochemistry in the present study: solid versus dotted bars indicate unambiguous versus ambiguous localization, respectively. Only bright, punctate labeling localized to sites of possible synaptic interaction are considered in this schematic. RT-PCR evidence for expression of $\mathrm{D} 1, \mathrm{D} 2$, and $\mathrm{D} 5$ in outer hair cells is not schematized here. $\mathrm{MOC}$ and $\mathrm{LOC}$ refer to the lateral and medial olivocochlear system, respectively. ISB, Inner spiral bundle; HP, habenula perforata; OSL, osseous spiral lamina.

immunohistochemical study in guinea pig has shown terminals in the IHC area that are immunopositive for D1 receptors (Niu and Canlon, 2006). A reverse transcriptase (RT)-PCR study suggested that D2 and D3 are present in mouse cochleas (Karadaghy et al., 1997). A combined RTPCR and immunohistochemical study has suggested that all five dopamine receptors are expressed in the rat cochlear nerve (Inoue et al., 2006).

Most pharmacological studies of cochlear dopaminergic signaling used classic agonist/antagonist agents such as piribedil (d'Aldin et al., 1995) and eticlopride (Ruel et al., 2001), which are poor at distinguishing among receptor subtypes. Recently, with application of more specific pharmacological agents, suppression of cochlear nerve response has been reported with perfusion of either D1/5 agonists or D2 antagonists (Garrett et al., 2011). Surprisingly, in this study, D2 antagonists also altered cochlear microphonics and distortion product otoacoustic emissions (DPOAEs), suggesting effects on $\mathrm{OHC}$ function despite the apparent lack of dopaminergic terminals in the $\mathrm{OHC}$ area (Eybalin et al., 1993; Darrow et al., 2006a; Fig. 1).

To address the gaps and contradictions in the existing literature, we have taken a multipronged approach to dopaminergic signaling in the inner ear. In the present study, we combine single-cell RT-PCR and immunohistochemistry to assess dopamine receptor expression and localization in the normal inner ear, and we parse the roles of the different dopamine receptors by studying the cochlear phenotype of mice from five mutant lines, each lacking one of the receptor subtypes.

\section{Materials and Methods}

\section{Experimental procedures}

Five mouse lines were studied, each with targeted deletion of one dopamine receptor subtype. The techniques used for the creation of each mutant line were described in prior reports: D1R nulls (Drago et al., 1994); D2R nulls (Kelly et al., 1997); D3R nulls (Accili et al., 1996); D4R nulls (Rubinstein et al., 1997); D5R nulls (Holmes et al., 2001). D1 mutants are smaller than their wild-type littermates and their postnatal development is slow. All other mutant lines lacking dopamine receptors were

synapse between IHC and cochlear nerve during acoustic overstimulation (Liberman and Mulroy, 1982; Robertson, 1983; Pujol et al., 1985).

Although many lines of evidence suggest that dopamine affects cochlear function, there is no consensus as to which receptors are mediating its effects. The dopamine receptor family includes five G-protein-coupled subtypes, from two major classes: D1 and D5 are coupled to the $G_{\alpha s}$-protein and activate adenylyl cyclase; D2, D3, and D4 are coupled to the $\mathrm{G}_{\alpha \mathrm{i}}$-protein and inhibit adenylyl cyclase (Beaulieu and Gainetdinov, 2011). An viable, fertile and appeared generally healthy with no gross behavioral or morphological abnormalities. All mutant lines were created as hybrids of 129 strains (stem cell donor) and C57BL/6NTac (maternal strain), then backcrossed with C57BL/6NTac mice for $>10$ generations. For each line, homozygous mutants were compared with wild-type controls. For two of the lines, the controls were littermates of the mutants, bred in our own laboratory from heterozygous parents (D1, D5). For other lines, both wild types and mutants were obtained from the laboratory that generated them (D2, D3, and D4). The care and use of the animals was approved by the animal care committee of the Massachusetts Eye \& Ear Infirmary. 
Table 1. PCR primer sets and expected amplicon size

\begin{tabular}{|c|c|c|c|c|}
\hline & First pair of $P C R$ primers & Amplicon (bp) & Second pair of $P C R$ primers & Amplicon (bp) \\
\hline \multirow[t]{2}{*}{ Nefh } & F: 5' -GGAGATGCCAGCGGCACCAG-3' & 457 & F: 5'-AGCCAGCCCCCAGAGAAGACC-3' & 186 \\
\hline & R: 5' -CCTGGGGAGGGTTTTCGGCG-3' & & R: 5' -GGGCAGGCCCACCATCTAAGC-3' & \\
\hline \multirow[t]{2}{*}{ Otoferlin } & F: 5'-TGAGGGGGTGGCTGAAGGGC-3' & 638 (isoform 1) & F: 5' -GAGATGGCCACCGGGGAGGT-3' & 232 \\
\hline & R: $5^{\prime}$-CAGCAGCGCCAGCACGATCT-3' & 841 (isoform 2) & R: 5'-ATGCCGTGTCAGGCCGGTTG-3' & \\
\hline \multirow[t]{2}{*}{ Chrna10 } & F: 5' -CACATTCTCCACAGCGCTTA-3' & 600 & F: 5'-TACCTGCCTGGGCTCGGGTC-3' & 251 \\
\hline & R: 5'-CAAAGGCTGTTTGTGGGTTT-3' & & R: 5' -ATCTTCATGGCGGCGCTGGG-3' & \\
\hline \multirow[t]{2}{*}{ DrD1a } & F: 5'-ACCTACATGGCCCTTGGATGGC-3' & 363 & F: 5' -CCCGTAGCCATTATGATCGT-3' & 15 \\
\hline & R: 5' -GGGAGCCAGCAGCACACGAA-3' & & R: 5'-ATTGAGAGCATTCGACAGGG-3' & \\
\hline \multirow[t]{2}{*}{ Drd5 } & F: $5^{\prime}-$ TGGGAGGAGGGGCAGTCACC-3' & 642 & F: 5' -GCTTTGCCAGTTGGTGCTCAGTG-3' & 134 \\
\hline & R: 5' -AGGTGGGCTCCTCCGTGAGC-3' & & R: 5' -GGCCCTTTGTTCTGCGAGTTCCC-3' & \\
\hline \multirow[t]{2}{*}{ DrD2 } & F: 5'-AGCCGCAGGAAGCTCTCCCA-3' & 284 & F: 5'-TGGCTGCCCTTCTTCATCACGC-3' & 157 \\
\hline & R: 5'-AGCTGCTGTGCAGGCAAGGG-3' & & R: 5'-TGAAGGCCTTGCGGAACTCAATGT-3' & \\
\hline \multirow[t]{2}{*}{ DrD3 } & F: 5'-CCTGTCTGCGGCTGCATCCC-3' & 252 & F: 5'-ATGGAGCACATAGAAGACAAACC-3' & 148 \\
\hline & R: $5^{\prime}$-TCTCCACTTGGCTCATCCC-3' & & R: $5^{\prime}$-AGTTTGGATGCCTCAAGGC-3' & \\
\hline \multirow[t]{2}{*}{ Drd4 } & F: 5'-TCCTGCCGGTGGTAGTCGGG-3' & 276 & F: 5'-GTGTGTTGGACGCCTTTCTT-3' & 218 \\
\hline & R: $5^{\prime}$-GCCAGCGCACTCTGCACACA-3' & & R: 5' -CTCCTTGACCTCTGCAGGAC-3' & \\
\hline
\end{tabular}

$F$, Forward; $R$, reverse.

\section{Gene expression}

Single-cell isolation in neonates. Cochleas of wild-type mice of both genders were dissected at postnatal day 11 (P11)-P13 in Leibovitz-15 medium supplemented with $10 \mathrm{~mm}$ HEPES, $\mathrm{pH}=7.4$. For isolation of single inner or outer hair cells, dissected cochlear coils from the apical or middle half turns were pinned to a glass coverslip in an extracellular solution comprising (in mM): $10 \mathrm{NaCl}, 6 \mathrm{KCl}, 1.5 \mathrm{CaCl}_{2}, 140 \mathrm{Na}$-gluconate, 2 Na-pyruvate, 10 Glucose, $10 \mathrm{HEPES}, 0.5 \mathrm{MgCl}_{2}$. Sampling from the apical-most $1 / 4$ turn was avoided, given the anatomical irregularities at the extremes of the cochlear duct. For aspiration of single spiral ganglion cells, the modiolus was extracted and treated with collagenase type IV $(0.5 \mathrm{mg} / \mathrm{ml})$ and trypsin $(2.5 \mathrm{mg} / \mathrm{ml})$ at $37^{\circ} \mathrm{C}$ for $30 \mathrm{~min}$, then triturated with a pulled Pasteur pipette. Cells were allowed to settle in Leibovitz-15 medium on a poly-D-lysine-coated glass-bottom culture dish for 2-4 h. Individual identified cells were aspirated with a glass electrode of tip diameter 5-10 $\mu \mathrm{m}$ under visual guidance with Nomarski optics (ganglion cells were readily distinguished from satellite cells, as confirmed in separate experiments with whole-cell patch-clamp recordings). The pipette tip was then broken and its contents expelled into a microcentrifuge tube containing PicoPure RNA Isolation Kit (Molecular DevicesArcturus) extraction buffer and RNase inhibitor. Sample pools, typically consisting of 6-20 individual cells of one type, were purified with the PicoPure kit, and amplified by in vitro transcription using the MessageBOOSTER cDNA Synthesis Kit for qPCR (Epicentre Biotechnologies).

The final cDNA product was used as template for amplification of dopamine receptors and cell type-specific markers (Table 1): (1) a neurofilament marker (Nefh, also called NF200) expressed in spiral ganglion cells (Dau and Wenthold, 1989), (2) the calcium sensor, otoferlin, expressed in inner hair cells (Roux et al., 2006), and (3) the nicotinic $\alpha 10$ receptor subunit expressed in both inner and outer hair cells until P21 (Elgoyhen et al., 2001). A first pair of PCR primers was used to amplify the locus of interest (Table 1). Each primer $(0.5 \mu \mathrm{M})$ was combined with $0.2 \mathrm{~mm}$ dNTPs, $2.5 \mathrm{U}$ of TaqDNA Polymerase, $1.5 \mathrm{~mm} \mathrm{MgCl}_{2}$ in $48 \mu \mathrm{l}$ of PCR buffer. The following PCR program was then run: $94^{\circ} \mathrm{C}$ for $2 \mathrm{~min} ; 40$ cycles of $94^{\circ} \mathrm{C}$ for $30 \mathrm{~s}, 55^{\circ} \mathrm{C}$ for $30 \mathrm{~s}$ (annealing temperature set $5^{\circ} \mathrm{C}$ below $\left.T_{\mathrm{m}}\right), 72^{\circ} \mathrm{C}$ for $1 \mathrm{~min}$; and $72^{\circ} \mathrm{C}$ for $10 \mathrm{~min}$. The amplified product $(1 \mu \mathrm{l})$ was used as template for a second set of primers (nested primers). The same PCR program was run as described above. The final amplified products were separated on a gel of $1 \%$ agarose, stained with ethidium bromide, and visualized on a UV transilluminator. For each primer set, a set of negative controls was prepared, substituting water for the reverse transcriptase, Taq polymerase or cDNA. In these cases, no bands were observed on agarose gels with any primer tested in these control samples. To confirm PCR product identity, amplified DNA was purified using QIAquick PCR Purification Kit (Qiagen) and sequenced (MGH DNA Sequencing Core, Cambridge, MA).

Quantitative RT-PCR. Cochleas were harvested from adult mice at 12 weeks of age. Following decapitation, both bullas were removed. The inner ear was exposed using forceps and inspected to ensure that no cerebellar tissue was included. Samples were kept frozen by immersion into liquid nitrogen until at least 3 samples of 2-3 cochleas were collected. Inner ears were then transferred to the appropriate volume of TRIzol Reagent (Invitrogen) and homogenized using the Omni Tip Homogenizing Kit (Omni International). RNA was prepared according to TRIzol Reagent manufacturers instructions following a first spin performed at $2500 \times g$ to sediment debris. RNA integrity was assessed using electropherograms generated on a RNA 6000 Nano Assay Chip (Agilent Technologies) and analyzed with the 2100 Agilent Bioanalyzer system. RNA concentration was assessed using a NanoDrop system (Thermo Fisher Scientific). Quantitative RT (qRT)-PCRs were performed on a Mx4000 Multiplex Quantitative PCR System (Stratagene) using the one step Quantitect SYBR Green RT-PCR kit (Qiagen), HotStarTaq DNA polymerase and primers designed to amplify the DNA fragment targeted in knock-outs (Table 1). Reactions were performed at least three times. Cycle-by-cycle and dissociation fluorescence data (melting curves) were collected. Analysis of relative fold change in gene expression was calculated as described previously (Stankovic and Corfas, 2003) using 18 S rRNA as a normalizing standard whereby the normalized gene expression (NGE) during the exponential phase of the PCR can be defined as: NGE $=E_{\mathrm{T}}^{-\mathrm{C}_{\mathrm{T}}} / E_{\mathrm{R}}^{-\mathrm{C}_{\mathrm{R}}}$, where $E_{\mathrm{T}}$ and $E_{\mathrm{R}}$ are, respectively, amplification efficiencies of the target and endogenous reference genes, and $C_{\mathrm{T}}$ and $C_{\mathrm{R}}$ are the mean threshold cycles for the target and reference genes, respectively.

\section{Cochlear response measures: auditory brainstem responses and DPOAEs}

Electrophysiological experiments were conducted in a soundproof chamber maintained at $\sim 32^{\circ} \mathrm{C}$. For measurement of auditory brainstem responses (ABRs) and DPOAEs, adult mice at 6-8 weeks were anesthetized with xylazine ( $20 \mathrm{mg} / \mathrm{kg}$, i.p.) and ketamine $(100 \mathrm{mg} / \mathrm{kg}$, i.p.) (Table 2). Acoustic stimuli were delivered using a custom acoustic assembly consisting of two electrostatic earphones (EC-1, Tucker Davis Technologies) to generate primary tones and a Knowles miniature microphone (EK-3103) to record ear-canal sound pressure. Stimuli were generated digitally with $4 \mu$ s sampling. Ear-canal sound pressure and electrode voltage were amplified and digitally sampled at $20 \mu \mathrm{s}$ for analysis of response amplitudes. Both outputs and inputs were processed with a digital I-O board (National Instruments 6052E).

For measurement of ABRs, needle electrodes were inserted at vertex and pinna, with a ground electrode near the tail. ABR potentials were evoked with $5 \mathrm{~ms}$ tone pips $\left(0.5 \mathrm{~ms}\right.$ rise-fall with a $\cos ^{2}$ onset, delivered at $35 / \mathrm{s})$. The response was amplified $(10,000 \times)$, filtered $(100 \mathrm{~Hz}-3 \mathrm{kHz})$, digitized, and averaged in a LabVIEW-driven data-acquisition system. Sound level was raised in $5 \mathrm{~dB}$ steps from $10 \mathrm{~dB}$ below threshold up to 80 dB SPL. At each sound level, 1024 responses were averaged (with stimulus polarity alternated), using an "artifact reject" whereby response wave- 
Table 2. Numbers of ears from each genotype in each physiological or histological analysis

\begin{tabular}{|c|c|c|c|c|c|}
\hline & D1 & D5 & D2 & D3 & D4 \\
\hline \multirow[t]{2}{*}{ Thresholds [ABR/DPOAE] } & $+/+=8$ & $+/+=11$ & $+1+=8$ & $+/+=13$ & $+/+=19$ \\
\hline & $-1-=7$ & $-1-=9$ & $-1-=8$ & $-/-=14$ & $-/-=19$ \\
\hline \multirow[t]{2}{*}{$\mathrm{OHC}$ efferent function } & $+1+=3$ & $+1+=6$ & $+1+=4$ & $+/+=4$ & $+/+=6$ \\
\hline & $-l-=1$ & $-1-=5$ & $-1-=4$ & $-1-=6$ & $-1-=6$ \\
\hline \multirow[t]{2}{*}{ Temporary threshold shift } & - & $+1+=6$ & $+1+=7$ & $+1+=6$ & $+/+=8$ \\
\hline & & $-1-=4$ & $-1-=8$ & $-1-=4$ & $-1-=8$ \\
\hline \multirow[t]{2}{*}{ Cochlear histopathology } & $+1+=2$ & $+1+=2$ & $+1+=2$ & $+1+=2$ & $+1+=2$ \\
\hline & $-1-=2$ & $-1-=2$ & $-1-=2$ & $-1-=2$ & $-1-=2$ \\
\hline
\end{tabular}

-, Not applicable.

forms were discarded when peak-to-peak amplitude exceeded $15 \mu \mathrm{V}$. Upon visual inspection of stacked waveforms, "threshold" was defined as the lowest SPL level at which any wave could be detected, usually corresponding to the level step just below that at which the peak-to-peak response amplitude rose significantly above the noise floor. For amplitude versus level functions, the wave-I peak was identified by visual inspection at each sound level and the peak-to-peak amplitude computed.

For measurement of DPOAEs at $2 f_{1}-f_{2}$, the primary tones were set so that the frequency ratio, $\left(f_{2} / f_{1}\right)$, was 1.2 and so that $f_{2}$ level was $10 \mathrm{~dB}$ below $f_{1}$ level. For each $f_{2} / f_{1}$ primary pair, levels were swept in $5 \mathrm{~dB}$ steps from $20 \mathrm{~dB}$ SPL to $80 \mathrm{~dB}$ SPL (for $f_{2}$ ). At each level, both waveform and spectral averaging were used to increase the signal-to-noise ratio of the recorded ear-canal sound pressure, and the amplitude of the DPOAE at $2 f_{1}-f_{2}$ was extracted from the averaged spectra, along with the noise floor at nearby points in the spectrum. Iso-response curves were interpolated from plots of DPOAE amplitude versus sound level. Threshold was defined as the $f_{2}$ level required to produce a DPOAE at $0 \mathrm{~dB}$ SPL.

\section{MOC assay}

Adult mice at $6-8$ weeks were anesthetized with urethane $(1.20 \mathrm{~g} / \mathrm{kg}$, i.p. $)$ and xylazine $(20 \mathrm{mg} / \mathrm{kg}$, i.p.) (Table 2$)$. A posterior craniotomy and partial cerebellar aspiration were performed to expose the floor of the IVth ventricle. To stimulate the olivocochlear bundle, shocks (monophasic pulses, $150 \mu$ s duration, 200/s) were applied through fine silver wires (0.4 mm spacing) placed along the midline, spanning the olivocochlear decussation. Shock threshold for facial twitches was determined, muscle paralysis induced with $\alpha$-D-tubocurarine (1.25 mg/kg, i.p.), and the animal connected to a respirator via a tracheal cannula. Shock levels were raised to $6 \mathrm{~dB}$ above twitch threshold. During the olivocochlear suppression assay, $f_{2}$ level was set to produce a DPOAE $10-15 \mathrm{~dB}>$ noise floor. To measure olivocochlear effects, repeated measures of baseline DPOAE amplitude were first obtained $(n=54)$, followed by a series of 70 contiguous periods in which DPOAE amplitudes were measured with simultaneous shocks to the olivocochlear bundle and additional periods during which DPOAE measures continued after the termination of the shock train.

\section{Acoustic overexposure}

Adult mice at $6-8$ weeks were exposed to free-field noise, while awake and unrestrained, in a small reverberant chamber (Table 2). Acoustic trauma was produced by a $15 \mathrm{~min}$ exposure to an $8-16 \mathrm{kHz}$ octave band noise presented at $94 \mathrm{~dB}$ SPL. The exposure stimulus was generated by a custom white-noise source, filtered (Brickwall Filter with a $60 \mathrm{~dB} /$ octave slope), amplified (Crown power amplifier), and delivered (JBL compression driver) through an exponential horn fitted securely to a hole in the top of a reverberant box. Sound exposure levels were measured at 4 positions within each cage using a 0.25 inch Bruel and Kjaer condenser microphone: sound pressure was found to vary by $<0.5 \mathrm{~dB}$ across these measurement positions.

\section{Cochlear processing and immunostaining}

Matched sets of wild-type and mutant adult mice (6-8 weeks) were perfused intracardially for assessment of histopathology via either plastic sections of osmium-stained cochleas, or organ of Corti whole mounts immunostained for tyrosine hydroxylase (TH) and vesicular ACh transporter (VAT) (Table 2). For plastic-embedded, sectioned material, intra- vascular fixative was $2.5 \%$ glutaraldehyde and $1.5 \%$ paraformaldehyde in phosphate buffer. Cochleas were osmicated, decalcified in EDTA, dehydrated in ethanols and propylene oxide, embedded in Araldite resins, and sectioned at $40 \mu \mathrm{m}$ on a Historange with a carbide steel knife. Sections were mounted on slides and coverslipped.

For immunostaining of cochlear whole mounts to assess the efferent innervation, intravascular fixation was with $4 \%$ paraformaldehyde (for $10 \mathrm{~min}$ to $2 \mathrm{~h}$, with or without $0.1 \%$ glutaraldehyde) in PBS. Cochleas were decalcified, dissected into half-turns and then incubated in 5\% normal horse serum (NHS) with $0.3 \%$ Triton X-100 in PBS for $1 \mathrm{~h}$. This was followed by incubation for $\sim 19 \mathrm{~h}$ in primary antibodies: (1) sheep anti-TH from Calbiochem (item \#657014) at 1:500, coupled with (2) rabbit anti-VAT from Sigma (item \#V5387) at 1:1000. The VAT antibody was labeled with a $1 \mathrm{~h}$ incubation in a biotinylated secondary followed by $1 \mathrm{~h}$ in a streptavidin-conjugated Alexa Fluor; the TH antibody received two sequential overnight incubations in complementary Alexa Fluorcoupled secondary antibodies (chicken anti-goat the first night, goat anti-chicken for the second). Cochlear lengths were obtained for each case, and a cochlear frequency map computed to precisely localize hair cells from the 5.6, 8.0, 11.3, 22.6, 32, 45.2 and $64 \mathrm{kHz}$ regions in each case. Confocal $z$-stacks of these 7 regions from each ear were obtained using a high-resolution (1.4 numerical aperture) oil-immersion objective and $2 \times$ digital zoom on a Leica TCS SP2. Image stacks were ported to an offline processing station, where $x y, x z$, and $y z$ projections were computed and recorded using an image-processing program (Amira, Visage Imaging).

Whole-mount preparations were also used for immunostaining to localize dopamine receptor subtypes in wild-type ears. Cochleae were fixed, decalcified, and dissected as above. The tissue was cryoprotected in $30 \%$ sucrose and frozen on dry ice; after thawing and rinsing in PBS, the pieces were incubated in 5\% NHS with $1 \%$ Triton X-100 in PBS for $1 \mathrm{~h}$, followed by incubation for $\sim 19 \mathrm{~h}$ in primary antibodies at $37^{\circ} \mathrm{C}$. Primary antibodies included: rabbit anti-D1 at 1:5000 (Calbiochem, catalog \#324390), rabbit anti-D2 at 1:500 (Millipore, catalog \#AB5084P), rabbit anti-D3 at 1:100 and 1:500 (Millipore, catalog \#AB1786P), and rabbit anti-D4 at 1:100 and 1:500 (Millipore, catalog \#AB1787P); antibodies were diluted in $1 \%$ NHS, with $1 \%$ Triton X-100. The antibodies were labeled with sequential $1 \mathrm{~h}$ incubations of either a biotinylated secondary followed by a streptavidin-conjugated Alexa Fluor, or complementary Alexa Fluor-conjugated secondary antibodies. In addition, a triple label was performed in conjunction with D2 labeling using goat anti- $\mathrm{Na}^{+} / \mathrm{K}^{+}$ ATPase $\alpha 3$ at 1:100 (Santa Cruz Biotechnology, catalog \#sc-16052) and mouse anti-synaptophysin at 1:100 (ICN, catalog \#69-730). Secondary incubations were performed in a $37^{\circ} \mathrm{C}$ oven as well with the following concentrations: biotinylated donkey anti-rabbit at 1:400, biotinylated donkey anti-mouse at 1:200; conjugates of Alexa Fluors 488 and 568 at 1:1000; conjugates of Alexa Fluors 633 and 647 at 1:200. All tissues were mounted and coverslipped in VectaShield (Vector Labs, catalog \#H-1000).

\section{Results}

\section{Expression levels and localization of dopaminergic receptors in the inner ear}

The dopaminergic innervation of the cochlea arises from the OC efferent system (Mulders and Robertson, 2004), which originates 
in the brainstem and projects to sensory cells and neurons in the inner ear. Immunohistochemical studies using tyrosine hydroxylase as a marker of catecholamine synthesis suggest that dopaminergic terminals in the cochlea are restricted to the IHC area, in both mouse (Darrow et al., 2006a) and guinea pig (Eybalin et al., 1993), where the primary targets are the postsynaptic terminals of cochlear nerve fibers (Liberman, 1980b; Fig. 1). Despite this reported expression pattern, cochlear perfusion of dopamine agonists and antagonists in guinea pig also affects cochlear responses generated mainly by OHCs (Garrett et al., 2011).

To clarify the site[s] of dopaminereceptor expression in the cochlea, we performed RT-PCR on microdissected cells from the organ of Corti. In immature ears (postnatal day 11-13), we dissected out the apical or middle cochlear turn and used pulled borosilicate glass tubing to aspirate individual IHCs, OHCs or spiral ganglion cells under direct visual control (Maison et al., 2010). Between 6 and 20 cells were collected for each cell type pool. RT-PCR analysis on agarose gels (Fig. 2A) revealed bands for D1 and D5 as well as D2 receptors in spiral ganglion cells and OHCs, but not in IHCs. D4 mRNA was detected only in spiral ganglion cells. Consistent results were seen for separate pools of cells collected on different days and analyzed with separate RT-PCRs (data not shown). D3 mRNA was never detected in any of the cell samples, although the appropriate D3 band was present in brain tissue (Fig. 2C). To verify the purity of our single cell type samples, we assayed mRNA for (1) the $200 \mathrm{kDa}$ neurofilament (Nefh) expressed in spiral ganglion neurons (Dau and Wenthold, 1989), (2) the presynaptic protein otoferlin expressed in inner hair cells (Roux et al., 2006) and (3) the $\alpha 10$ nicotinic acetylcholine receptor subunit (Chrna10) expressed in immature IHCs and OHCs (Elgoyhen et al., 2001). As expected, Nefh was seen only in spiral ganglion cell samples, otoferlin only in IHC samples, and Chrna10 in both IHC and OHC samples.

Single cell RT-PCR analysis was not successful in older ears, as cochlear explants do not survive long enough to perform the isolation and harvest on healthy cells. Thus, to determine whether mRNA expression changes during cochlear maturation, we performed quantitative RT-PCR analysis on 3 different samples of whole adult cochleas (6 ears for each sample). As seen in Figure 2B, D2 receptors were expressed at much higher levels than D1, D5 and D4. As seen for the single-cell type analysis, D3 expression was never detectable.

We also performed immunohistochemistry for dopamine receptors on cochlear tissue from adult ears. For D3, D4 and D5, staining was weak, inconsistent and/or nonspecific. Robust and localized staining was seen for D1 and D2 in cochlear nerve fibers in the neuropil beneath the IHCs (Figs. 3, 4). To clarify the precise tissue localization, we combined the D1 or D2 label with (1) an immunostain for a $\mathrm{Na}^{+} / \mathrm{K}^{+}$ATPase that selectively labels cochlear nerve

\section{B Adult - Whole Cochlea}

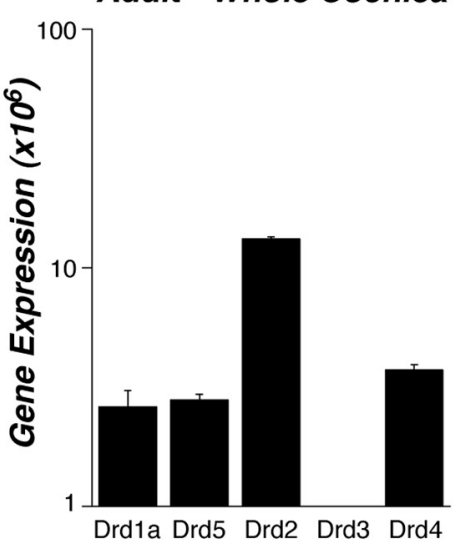

d

Adult - Control

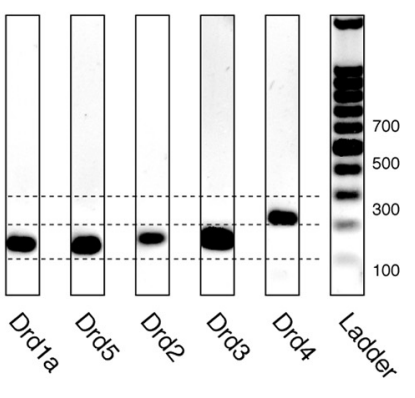

Figure 2. $\quad A-C, R T-P C R(A, C$ and $q R T-P C R(B)$ analysis of dopamine receptor expression in wild-type mice. $A, D 1, D 5$, and $D 2$ receptors were consistently expressed in $\mathrm{OHCS}$ and spiral ganglion neurons (SGNs), but not IHCs harvested from immature cochleas (P11-P13). D4 (Cors were expressed only in SGNs. Primers for neurofilament (Nefh), otoferlin, and the nicotinic receptor subunit $\alpha 10$ (Chrna10) were were never amplified. For the $q R T-P C R(B)$, mean expression levels are normalized to $185 \mathrm{rRNA}$, fter adjusting for primer efficiency, as (Stankovic and Corfas, 2003). Error bars represent SEMs. C, As a positive control for the primers, we showed that all five was set to 0 by subtracting the mean pixel value from an empty lane; gain was optimized by setting to 256 the mean pixel value from the 500 bp ladder band. Primer bands ( $<100 \mathrm{bp}$ ) are not shown.

afferents synapsing with IHCs (McLean et al., 2009) and (2) an immunostain for synaptophysin that selectively labels all terminals of the OC efferent system (Simmons et al., 1996).

In "surface views" of the cochlear epithelium (Fig. $3 A$ ), the confocal image projections show robust D2 staining of short segments of cochlear nerve fibers in the habenula perforata (red-fill arrow in Fig. $3 A$; arrow 1 in Fig. $3 C$ ), just at the transition between the myelinated peripheral axons (in the osseous spiral lamina) and the unmyelinated terminal (within the cochlear epithelium). This region, where the neuron is at its thinnest point (Liberman, 1980a), corresponds to the first node of Ranvier and likely also to the spike initiation zone of the cochlear nerve fibers (Hossain et al., 2005). The "side views" of the confocal stack, in which the voxels from 3 adjacent IHCs are viewed in maximum projection (Fig. $3 B, C$ ), reveals two other clusters of D2-positive puncta. Both are intimately associated with the synaptophysin-positive terminals of the OC system; however, one (arrow 2) is well beneath the bases of the IHCs while the other (arrow 3 ) is clustered near the terminal swellings of the cochlear nerve fibers, where synapses with IHCs are formed (Liberman, 1980b).

For D1, the triple-stained cochlear epithelia show immunolabel within the cytoplasm of the cochlear nerve terminals (Fig. $4 A$ ). The synaptophysin labeling reveals that the $\mathrm{D} 1$ label is again 

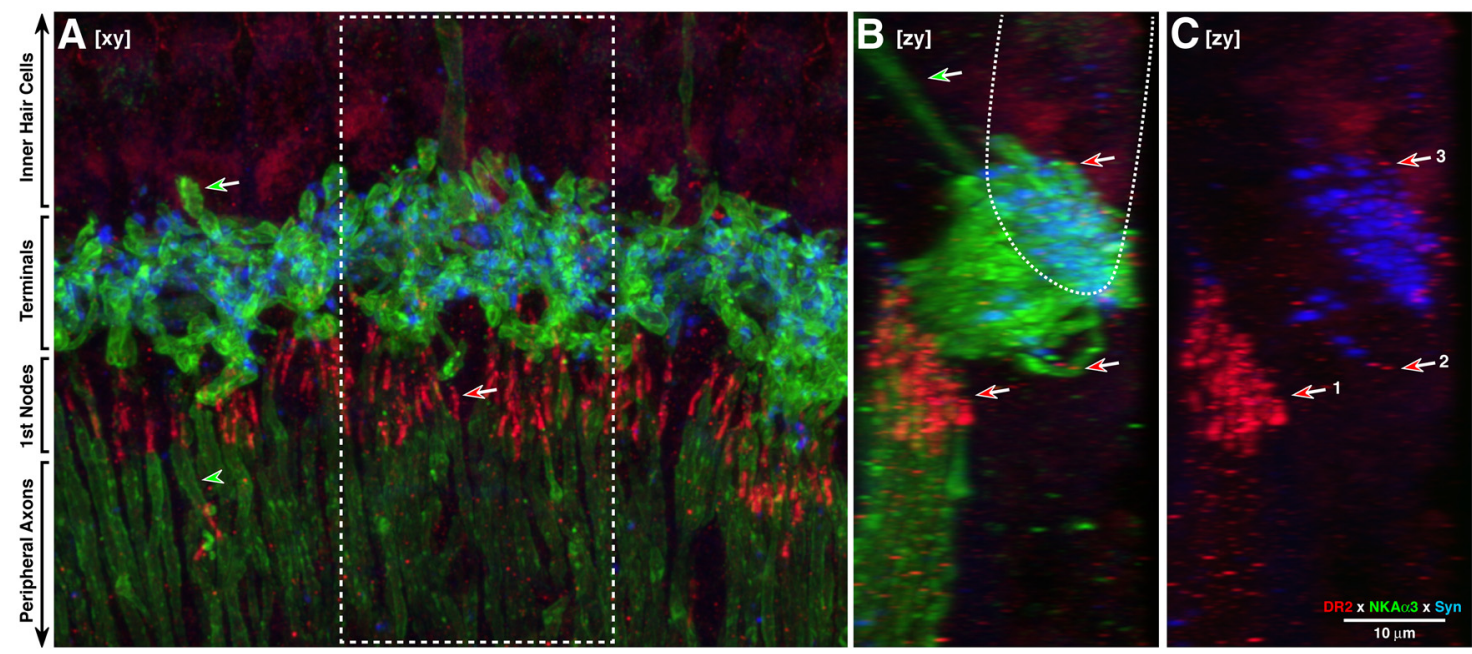

Figure 3. $A-C$, Immunostaining for D2 (red) shows receptor expression in cochlear nerve fibers, especially near the first nodes of Ranvier (red-filled arrows in $A$ and $C$ ), where the spike initiation zone is located. Cochlear nerve fibers are immunopositive for $\mathrm{Na}^{+} / \mathrm{K}^{+}$ATPase (green); olivocochlear terminals are immunopositive for synaptophysin (blue). $\boldsymbol{A}$, In this $x y$ projection (i.e., surface view of the sensory epithelium), cochlear-nerve peripheral axons are seen in the osseous spiral lamina (green-filled arrowhead), and their peripheral terminals are seen underneath the IHCs (green-filled arrow), where 0 C terminals contact them. $B$, C, Side views, i.e., zy projections, of the dashed subregion in $\boldsymbol{A}$. In $\boldsymbol{C}$ the green channel has been eliminated to better view the small D2-positive puncta clustered near the two clouds of synaptophysin-positive 0 C terminals (red-fill arrows in $\boldsymbol{B}$ and $\boldsymbol{C}$ ). The approximate outline of the IHCs in these zy projections is indicated by the dotted line in $\boldsymbol{B}$, and efferents to the $\mathrm{OHC}$ are indicated by the green-fill arrow. All images are maximum projections from a confocal $z$-stack obtained at the $8.0 \mathrm{kHz}$ region of a wild-type. Scale bar in Capplies to all panels. Numbered arrows in C show D2-positive puncta: arrow 1 points to the first nodes of Ranvier; arrows 2 and 3 point to two regions within the inner spiral bundle, below, and at the level of, the IHC bases, respectively.

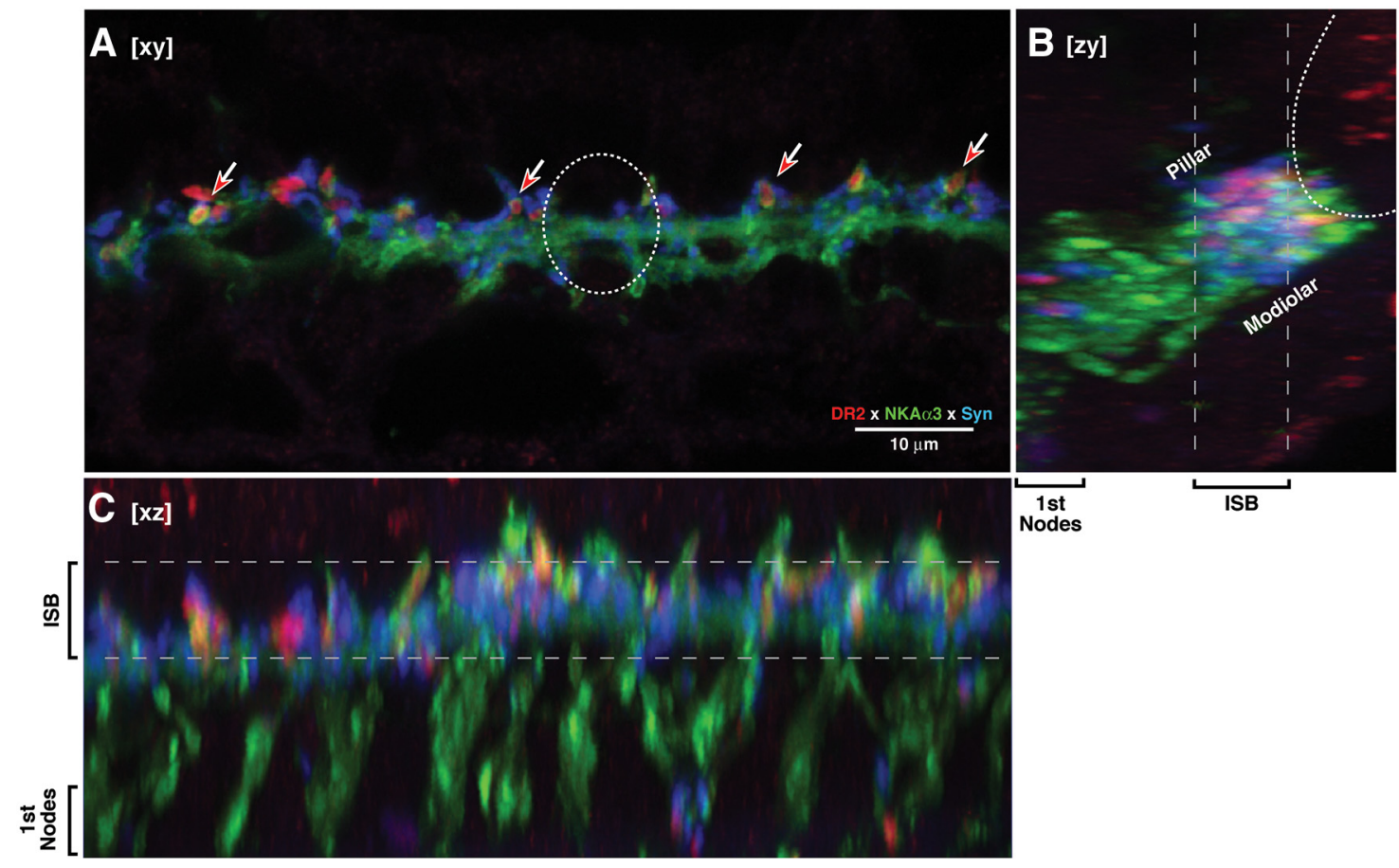

Figure 4. Immunostaining for D1 (red) shows receptor expression in cochlear nerve terminals, especially in the inner spiral bundle (ISB) area and the region of the first nodes of Ranvier, where synaptophysinpositive terminals of the $O C$ system are concentrated. $A$, Confocal $x y$ projection shows, in surface view, a $5 \mu \mathrm{m}$ slab of the neuropil under the IHCs (i.e., maximum projection from 20 of the $80 \mathrm{z}$-slices, centered on the ISB, as indicated by the dashed lines in $\boldsymbol{B}$ and $\boldsymbol{C}$. D1 immunolabel is seen in cochlear nerve terminals (green), which appear in cross section in the xy projection (red-filled arrows). Approximate size and location of an IHC is shown as a dotted circle. $\boldsymbol{B}, \boldsymbol{C}$, Thezy and $x z$ projections, respectively, of all 80 sections of thez-stack. The zy projection $(\boldsymbol{B})$ shows the IHC area shown as in a cross-section through the epithelium (e.g., Fig. 1); the xz projection (C) shows the view from the tunnel of Corti. All images are from the $8.0 \mathrm{kHz}$ region of a wild-type ear. Scale bar in $\boldsymbol{A}$ applies to all panels.

restricted to the regions of the nerve terminals where they are contacted by terminals of the OC system: i.e., (1) in the inner spiral bundle near the IHC/cochlear-nerve synapses and (2) in the region of the habenula perforata, just peripheral to the first nodes of Ranvier (Fig. 4B,C). The cross-sectional view of the IHC area, seen in the $z y$ projection (Fig. $4 B$ ), suggests that $\mathrm{D} 1 \mathrm{immu}$ noreactivity is stronger in nerve terminals on the pillar-facing side of the IHC: the cochlear nerve fibers on this side of the IHC are those with low-thresholds and high rates of spontaneous discharge (Liberman et al., 2011). 


\section{Cochlear phenotypes with targeted deletion of dopamine receptors}

To assess the role of dopamine receptors in the auditory periphery, we studied cochlear physiology and morphology in mice with targeted deletion of each of the dopamine receptors: D1-like receptors (D1 and D5) and D2-like receptors (D2, D3 and D4). As described in prior publications, the D2, D3, D4 and D5 mutant lines display no gross structural or behavioral abnormalities and are otherwise viable and fertile. In contrast, mice from the D1 line are significantly smaller than normal, have abnormal locomotor activity and poor survival beyond a few weeks of age, which limited the range of testing that could be performed.

Histopathology of the cochlear duct and its innervation Cochlear morphology in knock-outs and wild types was assessed by light microscopic evaluation of plastic sections of aldehydefixed and osmium postfixed cochleas (Fig. 5). No systematic abnormalities were seen in any structure of the inner ear, including hair cells and spiral ganglion cells, stria vascularis, spiral ligament and all supporting structures of the cochlear duct. For each case evaluated, serial sections through the entire cochlea were examined. Special attention was paid to the basal-turn hair cells and to the type-IV fibrocytes in the spiral ligament, which are the most vulnerable elements in a number of hearing-loss mouse models including acoustic injury (Wang et al., 2002) and age-related hearing loss (Hequembourg and Liberman, 2001), as well as in other receptor mutants we have examined, e.g., GluR $\delta 1$, GABA$\mathrm{A} \alpha 5$ and GABA-A $\beta 2$ (Maison et al., 2006; Gao et al., 2007).

To examine the olivocochlear efferent innervation, in general, and the dopaminergic efferent subgroup, in particular, we double-immunostained cochleas with cholinergic and dopaminergic markers. As described previously (Darrow et al., 2006a), in normal mice, antibodies to the VAT, label the majority of efferent terminals in both inner and outer hair cell areas, whereas $\mathrm{TH}$ labels a distinct minority population (which is VAT negative) in the IHC area only. The normal distribution of VAT-positive and TH-positive terminals were present in a D2 knock-out ear. As described in guinea pig (Mulders and Robertson, 2004), the density of TH-positive fibers was higher in the basal half of the cochlea. In all, 4 knock-out ears and 4 wild-type ears were qualitatively assessed (data not shown). For other mutant lines, our assessment of OC efferent system was restricted to functional analysis of its peripheral effects (see below).

\section{Cochlear thresholds and suprathreshold responses}

We assessed cochlear function by both ABRs and DPOAEs, because the combination can differentiate OHC-based dysfunction (reflected in DPOAEs) from that arising further "downstream," i.e., in the IHC or spiral ganglion cell (as seen in ABRs). Both ABR and DPOAE data were gathered in such a way as to allow both (1) a measure of the threshold of response, i.e., the lowest stimulus level required to produce a criterion response, just above the measurement noise floor, and (2) the growth of response magnitude with sound pressure level.

Deletion of D3, D4 or D5 receptors had no impact on cochlear thresholds, as measured by either DPOAEs or ABRs, or on the amplitudes of suprathreshold DPOAE or ABRs at any of the test frequencies (Fig. 6). Suprathreshold amplitudes are shown in
Figure 6 only for stimuli at 8 or $32 \mathrm{kHz}$, however similar results were obtained at all other test frequencies.

In contrast, deletion of D1 or D2, did have small, but significant, impact on baseline cochlear responses to sound. Interestingly, the effects were in opposite directions, as might have been predicted from observations in other neural systems that D1, a $\mathrm{G}_{\alpha \mathrm{s}}$-protein-coupled receptor, and D2, a $\mathrm{G}_{\alpha \mathrm{i}}$-protein-coupled receptor, tend to elicit complementary downstream effects. In D1nulls, responses were enhanced. ABR thresholds were enhanced by $5-20 \mathrm{~dB}$ across all test-frequencies ( $p=0.04$ by two-way ANOVA), while DPOAE thresholds were significantly improved only at high frequencies $(p<0.001)$. Correspondingly, suprathreshold amplitude enhancement in D1 nulls was seen for ABR wave 1 , the summed activity of spiral ganglion neurons at both 8 and $32 \mathrm{kHz}$, whereas DPOAE suprathreshold amplitudes were only enhanced at high frequency. In D2-nulls, cochlear responses were attenuated. ABRs showed $\sim 5-10 \mathrm{~dB}$ threshold elevation at all frequencies $(p=0.003)$, whereas DPOAE thresholds were significantly elevated only at high frequency $(\geq 32 \mathrm{kHz})$. Correspondingly, suprathreshold responses were attenuated, but only for high-frequency stimuli.

\section{Vulnerability to acoustic injury}

Several lines of evidence suggest that the cochlea's dopaminergic innervation plays a role in minimizing glutamate excitotoxicity at the IHC/afferent synapse following acoustic overexposure (d'Aldin et al., 1995; Ruel et al., 2001). Notably, selective removal of OC efferents to the IHC area, and thus removal of dopaminergic projections to the inner ear, resulted in increased noise-induced threshold shift, when measured by ABRs, but no change in the noise-induced shifts measured by DPOAEs (Darrow et al., 2007).

To assess the role of individual dopamine receptor subtypes in such putative neuroprotection, we exposed age- and sexmatched groups of mutant and wild-type animals to a $94 \mathrm{~dB}$ SPL noise band designed to produce a severe, but ultimately reversible, threshold shift. Acoustic injury in D1 knock-outs was not assessed due to the overall poor physical condition of the animals in this mutant line.

As summarized in Figure 7, dopamine-mediated protection was suggested by the noise-induced threshold shift data for 3 of the 4 lines tested. The lack of effect on noise vulnerability in the D3 mutant is consistent with the apparent lack of D3 expression in the mouse cochlea (Fig. 2). For the D4 and D5 mutants, the phenotype suggested the expected neuroprotective effect, i.e., a statistically significant increase in threshold shift as measured by ABRs (D4: $p=0.044$; D5: $p=0.042$ by two-way ANOVA), without a significant difference as measured by DPOAEs. For the D2 mutants, the data suggested dopamine-mediated protection; however, the differences were present in both DPOAE ( $p=$ 

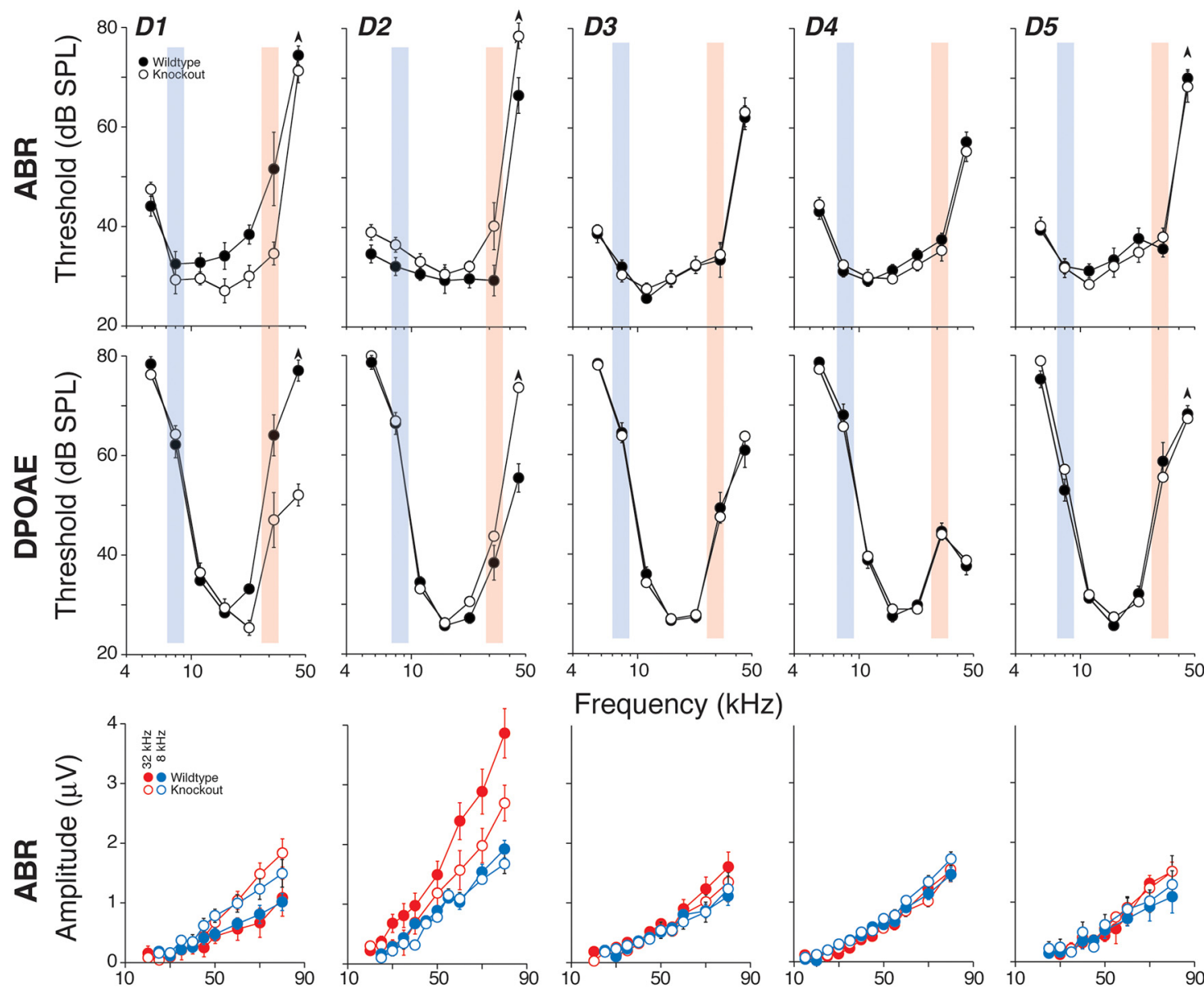

Frequency $(\mathrm{kHz})$
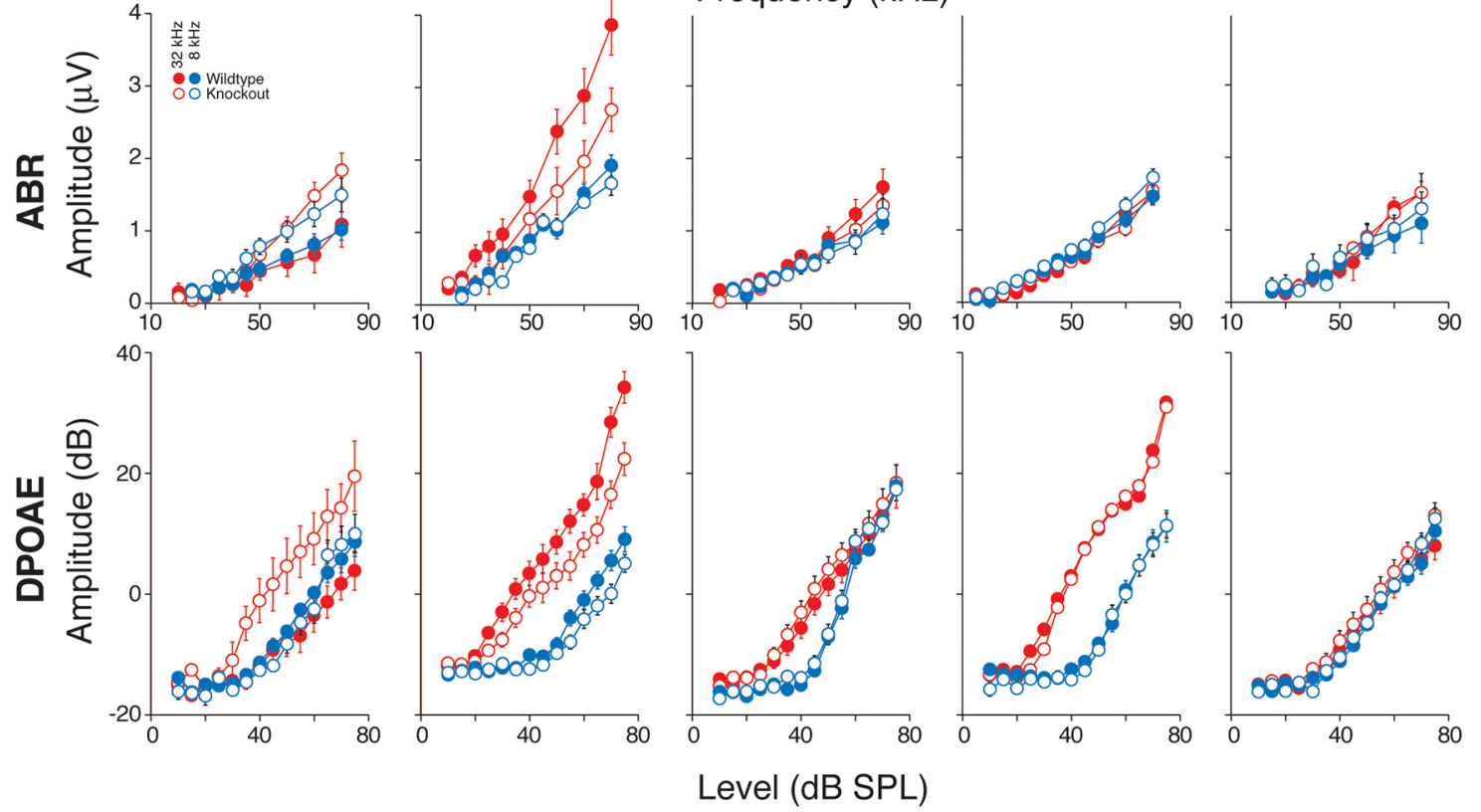

Figure 6. Deletion of D1 or D2 receptors enhanced or degraded cochlear sensitivity, respectively, whereas deletion of D3, D4, or D5 had no measurable effect. Each column shows a different mutant line compared with its wild-type littermates: numbers tested for each group are in Table 2. Group means ( \pm SEMs) are shown: thresholds versus frequency in the top rows and amplitudes versus level in the bottom rows. The blue and red shading in the top rows identifies the frequencies ( $8.0 \mathrm{and} 32 \mathrm{kHz}$ ) shown for amplitude versus level functions in the bottom rows. For ABR amplitudes, only wave 1 was measured. Symbol keys in the first column apply to all columns. Up-arrows on some threshold points indicate that some animals in the group had thresholds at that frequency $>80 \mathrm{~dB}$ SPL, the maximum level routinely tested.

$0.011)$ and ABRs $(p=0.041)$, suggesting a protective effect of dopaminergic transmission mediated via the OHCs.

\section{Olivocochlear efferent function}

Complementing the idea that dopaminergic OC efferents to the IHC area may protect the cochlear nerve from noise damage, the cholinergic OC efferents are known to protect the OHCs from noise damage (Maison et al., 2002). Electron microscopic evidence suggests that efferents in the IHC area may synapse on the MOC efferents to the $\mathrm{OHC}$ area as they pass through the IHC region (Liberman, 1980a). Thus, we wondered whether attenuation of OHC efferent feedback by loss of this putative efferent-efferent synaptic interaction in a D2 recep- tor mutant might explain the increased vulnerability of OHCs in this line. The OHC efferents form the effector arm of a sound-evoked negative feedback pathway, whose activation decreases the normal contribution of OHCs to cochlear amplification. Thus, activation of the MOC efferents by electrical stimulation in the brainstem, suppresses DPOAEs (Fig. 8A). This suppression provides a sensitive measure of OC function. Therefore, we investigated whether the loss of dopamine receptors affected the time course or magnitude of the OC effect on OHCs.

DPOAE amplitudes evoked by low-level tones were measured before, during and after delivering a $70 \mathrm{~s}$ shock train to the OC 

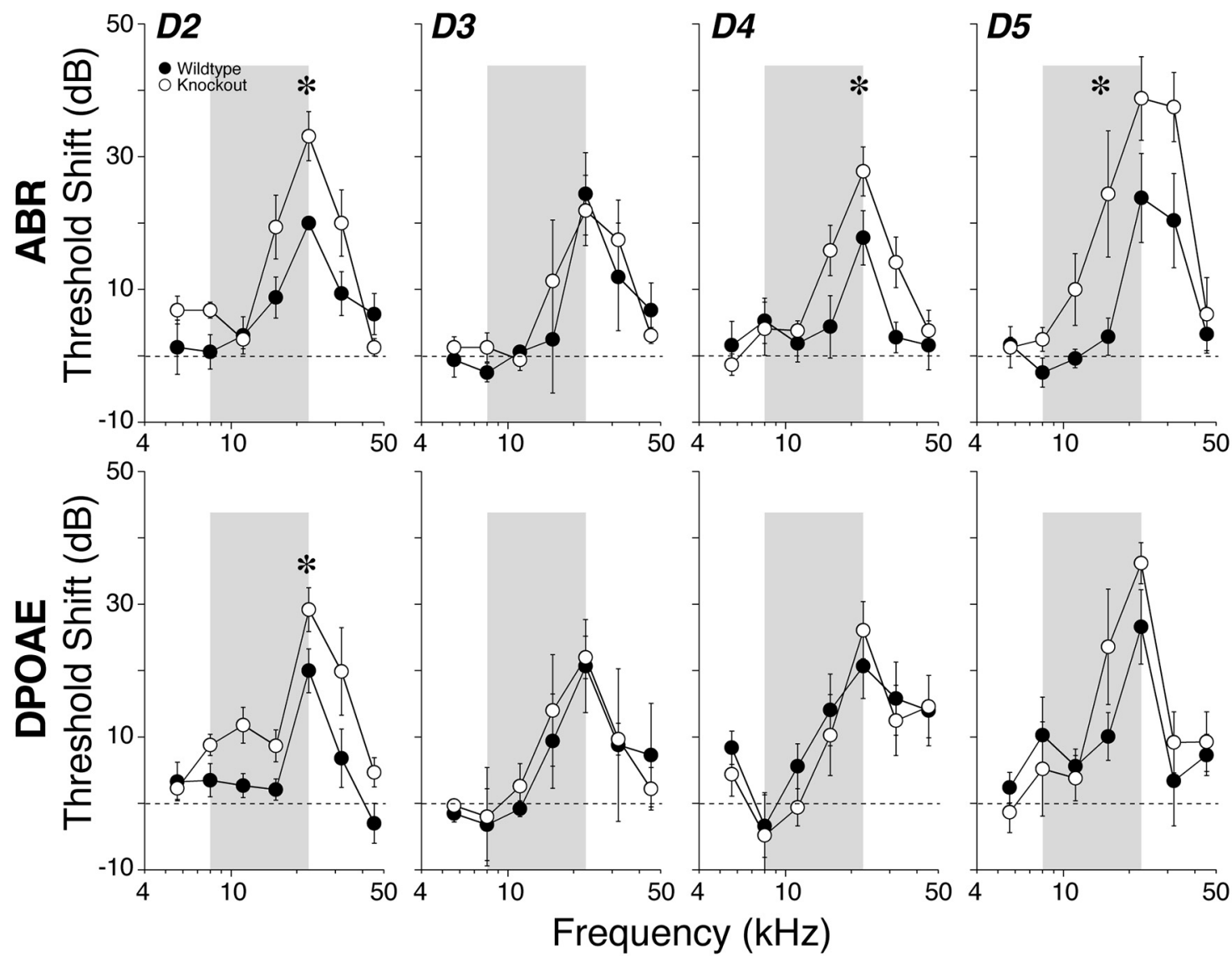

Figure 7. Vulnerability to acoustic injury is increased by loss of D2, D4, and D5Rs as measured $6 \mathrm{~h}$ after exposure to an $8-16 \mathrm{kHz}$ noise band (gray bars) at $94 \mathrm{~dB}$ for $15 \mathrm{~min}$. The mean threshold shift increase ( \pm SEM) observed in D2 knock-outs can be measured using both ABR and DPOAE metrics; however, the increase in sensitivity to acoustic injury is revealed in D4 and D5 knock-0uts only when using ABR metrics. Symbol key in the D2 panel applies to all panels. Asterisks indicate statistical significance by two-way ANOVA.

bundle at the floor of the $\mathrm{IV}^{\text {th }}$ ventricle. Figure 8 shows one run measured at $f_{2}=16 \mathrm{kHz}$ in a $\mathrm{D} 4$ mutant. Qualitatively, OC effects were normal in each line of dopamine receptor knock-out mice: (1) at shock-train onset, DPOAE amplitudes were suppressed (Fig. 8, top); (2) this suppression was maximal for tones at 16-22 $\mathrm{kHz}$ reflecting the innervation density of $\mathrm{OC}$ terminals along the cochlear spiral in mouse (Maison et al., 2003); (3) suppression decayed during the $70 \mathrm{~s}$ shock train as is observed in auditory nerve response (Wiederhold and Kiang, 1970); and (4) a slow enhancement of DPOAEs (Maison et al., 2007) was usually visible after termination of the shock train. Quantitatively, the magnitude of efferent-mediated cochlear suppression was unchanged in D1, D3, D4 and D5 mutants (Fig. 8, bottom). In D2 knockouts, there was a significant decrease in the mean magnitude of efferent-mediated cochlear suppression $(p<0.001$ by two-way ANOVA), at test frequencies $>22 \mathrm{kHz}$ (Fig. 8 , bottom).

\section{Discussion}

Dopaminergic innervation and dopamine receptor expression in the cochlea

The dopaminergic innervation of the inner ear has been most extensively studied in the guinea pig (Jones et al., 1987; Eybalin et al., 1993; Mulders and Robertson, 2004) and mouse (Darrow et al., 2006a). In both species, some of the spiraling fibers in the IHC area are immunopositive for TH, the enzyme catalyzing the first step in catecholamine synthesis, but immunonegative for dopamine $\beta$-hydroxylase, the enzyme that converts dopamine to noradrenaline. In guinea pig, retrograde tracers show these dopaminergic fibers originate in the lateral superior olive, and thus comprise a component of the LOC system. The dopaminergic LOC neurons are found predominantly in the high-frequency limb of the LSO, consistent with a predominant projection of TH-positive terminals to the (high-frequency) basal half of the cochlea (Mulders and Robertson, 2004). Doubleimmunostaining in mouse shows that the dopaminergic and cholinergic components of the LOC system are distinct subgroups, with little or no transmitter colocalization (Darrow et al., 2006a).

The major peripheral targets of all LOC neurons, regardless of their cytochemistry, are the unmyelinated terminals of cochlear nerve fibers in the IHC area (Liberman, 1980b), and immunoelectron microscopy shows synapses between TH-positive terminals and cochlear nerve dendrites (Eybalin et al., 1993). Correspondingly, our single-cell RT-PCR data showed evidence for expression of four of the five dopamine receptors (all except D3) in cochlear neurons (Fig. 2A). Our qRT-PCR of whole cochlear homogenates also failed to amplify D3 receptors (Fig. 2B). Although a prior PCR study suggested that all five dopamine receptors are expressed in rat cochlea (Karadaghy et al., 1997), tissue contamination from nearby neuronal structures (e.g., cerebellum, geniculate ganglion, etc.) could explain the discrepancy. A putative absence of $\mathrm{D} 3$ cochlear expression fits with the observed lack of phenotype in D3-null ears (Figs. 6, 7).

Our immunohistochemical data (Figs. 3, 4) confirm expression of D1 and D2 receptors in the unmyelinated terminals of cochlear nerve fibers. The D1-positive fibers in the IHC area (Fig. 4) can be confidently identified as cochlear nerve fibers, because 


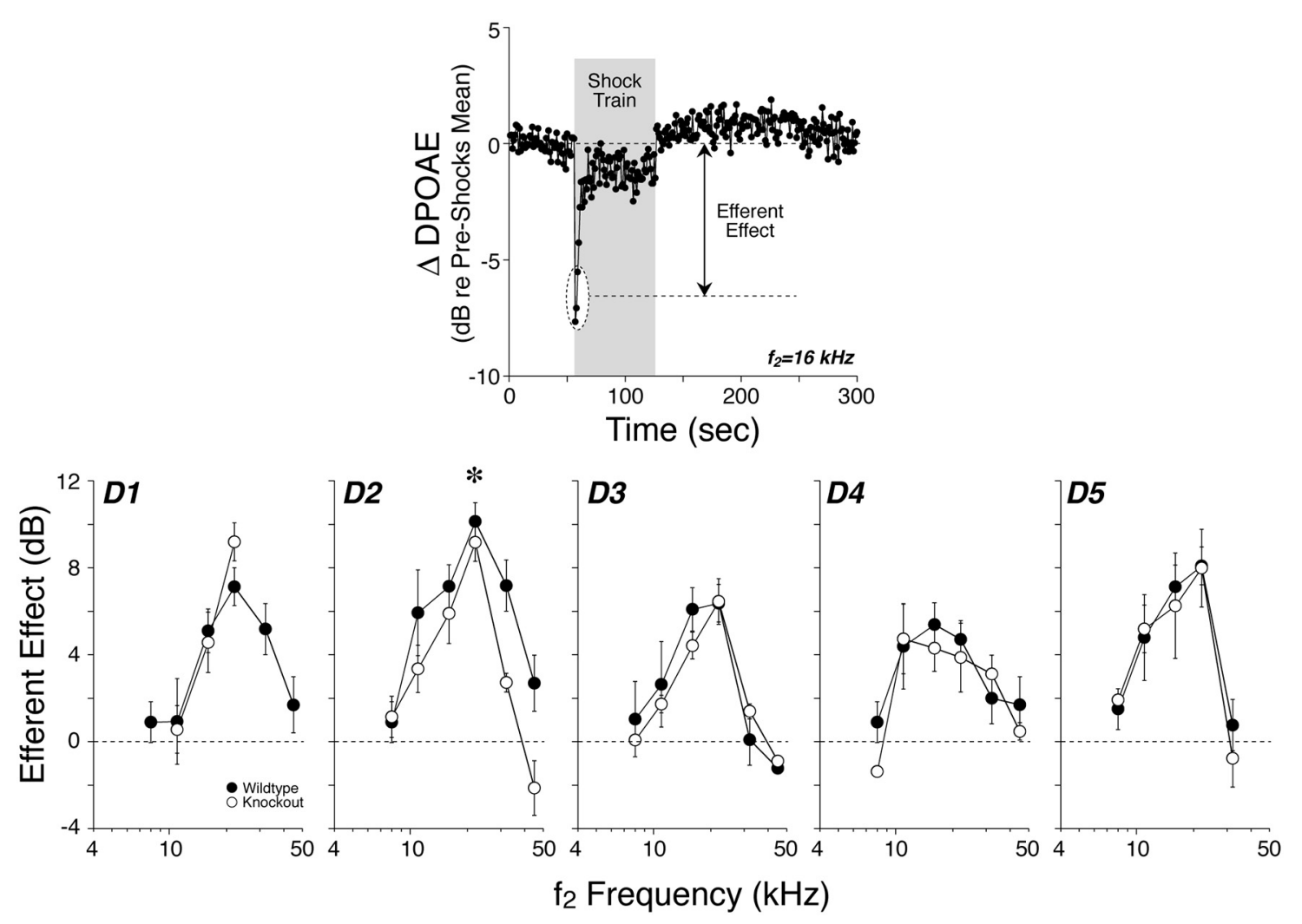

Figure 8. Cochlear effects of activating the medial olivocochlear efferents are undiminished by deletion of dopamine receptors, except for the D2R-nulls. To assay efferent effects, DPOAE amplitudes evoked bylow-level tones are measured before, during, and after delivering a 70 sshock train to the olivocochlear bundleat the floor of the IVthventricle. Top, One "run" of the assay shows DPOAE amplitudes, normalized to the mean pre-shock value. Efferent effect is defined as the difference between the pre-shock mean and the mean DPOAE amplitude for the first three measures taken after shock-train onset. Bottom, Mean efferent effect size ( \pm SEM) for wild-type versus dopamine receptor-null ears for each of the 5 lines tested. Asterisk (D2 only) indicates statistical significance by two-way ANOVA.

(1) they are immunopositive for the isoform of $\mathrm{N}^{+} / \mathrm{K}^{+}$ATPase that labels these IHC afferents (McLean et al., 2009), and (2) the fibers can be traced, in confocal $z$-stacks, to terminal swelling on the bases of IHCs - a trajectory and termination inconsistent with MOC fibers, the only other cochlear elements immunopositive for this ATPase isoform (McLean et al., 2009). Although the D1 protein does not appear localized to postsynaptic membranes, the immunostaining is restricted to regions of the postsynaptic terminals where the dopaminergic OC terminals are found (Darrow et al., 2006a): the anti-synaptophysin immunostaining (blue in Figs. 3, 4) stains both cholinergic and dopaminergic components. This apposition of dopaminergic terminals and receptors suggests the presence of functional signaling units.

The D2-positive fibers in the habenula perforata (Fig. 3) must also correspond to cochlear nerve fibers innervating IHCs, since (1) they are immunopositive for the $\mathrm{N}+/ \mathrm{K}^{+}$ATPase and (2) because these IHC afferents greatly outnumber the (ATPase-positive) MOC neurons in this region (Liberman, 1980a). Receptor localization to the neuronal membranes in the habenula is functionally significant, because this region corresponds to the first node of Ranvier and, presumably, the spike initiation zone (Hossain et al., 2005). However, a habenular localization is also curious, because the closest dopaminergic LOC terminals are 5-15 $\mu \mathrm{m}$ away. within the lower portion of the inner spiral bundle (Fig. 1). Although extrasynaptic effects of dopaminergic transmission have been described (Vizi and Lábos, 1991), these are typically over shorter distances.

The D2 immunostaining also showed small puncta localized within the clusters of LOC terminals in the inner spiral bundles (e.g., arrows labeled 2 and 3 in Fig. 3C). Because this region of the neuropil is so complex, and because ultrastructural studies have also docu- mented synapses between LOC terminals and IHCs or MOC fibers (Liberman, 1980b; Liberman et al., 1990), the cellular localization of these D2-positive puncta is ambiguous. Since we failed to amplify D2 receptors from isolated IHCs (Fig. 2A), we have not included dopamine receptors on IHCs in the schematic summary (Fig. 1). However, in addition to a possible LOC/MOC synapse, the possibility of presynaptic dopamine receptors in the LOC terminals cannot be ignored given the in vitro studies of stimulated dopamine release and its modulation via dopamine receptor antagonists (Gáborján et al., 1999; Halmos et al., 2005). Another report describes sparse terminalsized puncta in the IHC area immunopositive for a combination of D2 and D3 antibodies, however, without other markers, the nature of the immunostained elements they report is also ambiguous (Inoue et al., 2006).

\section{Pharmacological effects versus knock-out phenotypes}

Cochlear perfusion of dopamine reduces sound-evoked neural responses, i.e., cochlear compound action potential (CAP) or singlefiber action potentials, without altering hair-cell generated potentials, such as the cochlear microphonic or the summating potential (Ruel et al., 2001). Similarly, nomifensine-mediated block of the dopamine transporter expressed in LOC terminals in the IHC area (Ruel et al., 2006), reduces the CAP without affecting DPOAEs, presumably by increasing dopamine concentration in the neuropil underneath the IHCs. The inhibitory effects of dopamine are likely mediating the slow-onset neural inhibition that can be observed when activating the LOC system electrically (Groff and Liberman, 2003).

Studies addressing the nature of the dopamine receptors mediating this inhibitory effect provide support for both D1-like 
(Niu and Canlon, 2006; Garrett et al., 2011) and D2-like (d'Aldin et al., 1995) pharmacology; however, the combined claims are both contradictory and paradoxical. Contradictory claims, e.g., that the D1/D5 agonist SKF38393 enhances (Niu and Canlon, 2006) or suppresses (Garrett et al., 2011) the CAP in guinea pig, are hard to reconcile. Paradoxical reports, e.g., that receptor antagonists (SCH23390 - D1 or eticlopride-D2/D4), like dopamine itself, also reduce CAP (Ruel et al., 2001), may reflect the complex interplay between presynaptic and postsynaptic receptors: blocking presynaptic receptors on LOC terminals may increase dopamine concentration in the IHC neuropil (Gáborján et al., 1999) and thus have the same effect as activating postsynaptic receptors on cochlear neurons. Although in other systems, D2like receptors can be presynaptic (Beaulieu and Gainetdinov, 2011), cochlear dopamine release studies report both D1-like (Gáborján et al., 1999) and D2-like (Halmos et al., 2005) pharmacology, based on agonist/ antagonist effects on electrically evoked release. Outcomes are further complicated by the fact that the differences in receptor specificity of the various agonists and antagonists are typically quantitative not qualitative, and most cochlear studies do not construct complete does-response curves.

The small but significant changes we observed in cochlear baseline responses in the individual receptor knock-out lines (Fig. 6) cannot resolve these issues: three of the lines (D3, D4, and D5) have no change in baseline cochlear function, and the changes in the two other (D1 and D2), rather than reflecting only neural modulation, appear to arise in the $\mathrm{OHC}$ area. Putative dopaminergic effects in the $\mathrm{OHC}$ area are not unprecedented: cochlear perfusion of a D2 antagonist (PD128907) greatly suppresses both DPOAEs and CAPs (Garrett et al., 2011). Although we saw expression of D1, D5 and D2 receptors in OHCs in the neonatal ear (Fig. 2), there is unanimity in the literature concerning the absence of dopaminergic fibers in the OHC area of the adult cochlea (Eybalin et al., 1993; Niu and Canlon, 2002; Mulders and Robertson, 2004; Darrow et al., 2006a). The possible developmental release of dopamine from MOC terminals in the $\mathrm{OHC}$ area is a possible interpretation. Alternatively, dopaminergic effects on the OHCs could be mediated via LOC synapses on the MOC innervation of OHCs (Liberman, 1980b): indeed, we observed a decrease in the effectiveness of MOC activation in the D2 knockout line (Fig. 8). MOC function appears to be necessary for normal development of the OHCs (Maison et al., 2006); whereas loss of the entire OC efferent system in the adult does not affect cochlear thresholds (Liberman, 1990), loss during development causes severe OHC dysfunction (Walsh et al., 1998), as does constitutive loss of the LOC transmitter urocortin (Vetter et al., 2002). Extrasynaptic effects from dopamine (or urocortin) release in the IHC area during development are a logical possibility (Lendvai et al., 2011), although the distances involved (50-100 $\mu \mathrm{m})$ seem long for efficient diffusion.

\section{Dopamine and excitotoxicity in the cochlear nerve}

Acoustic overstimulation can lead to a type of glutamate excitotoxicity in the cochlear nerve, seen as swelling of their terminal swellings on the IHCs immediately after exposure (Liberman and Mulroy, 1982; Robertson, 1983; Pujol et al., 1985). This excitotoxicity rapidly causes disappearance of the synapses and retraction of the unmyelinated nerve terminals, followed by a slow death of the spiral ganglion cells, even in the absence of lasting threshold shift or sensory cell damage (Kujawa and Liberman, 2009).

A role for dopaminergic signaling in the control of this excitotoxicity is suggested by the fact that terminal swelling can be mimicked by perfusion of D2/D4 antagonist eticlopride (Ruel et al., 2001) and the D2/D3/D4 antagonist piribedil protects against noise-induced swelling (d'Aldin et al., 1995). It may not be a coincidence that the dopaminergic innervation in the IHC area is richer in the basal half of the cochlea (Mulders and Robertson, 2004) where the phenomenon of excitotoxicity is more pronounced (M. C. Liberman, unpublished observation).

Present results further support the notion of dopaminergic suppression of excitotoxicity. As shown in Figure 7, when we overexposed dopamine receptor knock-out lines to noise, 3 of 4 mutant lines tested showed heightened vulnerability, and 2 of the lines (D4 and D5) showed significant exacerbation of neural threshold shifts, without a significant change in the OHC-based damage. A similar increase in the noise vulnerability of cochlear neurons, without any change in baseline cochlear thresholds, is seen after removal of the entire LOC system (Darrow et al., 2007). It is possible that in the absence of dopaminergic modulation, the cochlear nerve would be damaged by even moderate levels of noise, since cochlear nerve fibers have a narrow dynamic range (Winter et al., 1990) and are driven to their maximum discharge rates by sounds only $20-50 \mathrm{~dB}$ above threshold levels. It may be significant, in this regard, that the distribution of D1 immunoreactivity among cochlear nerve terminals seemed biased toward the fibers with low thresholds and high spontaneous rates (SRs): an SR-related difference in DR expression could underlie the heightened vulnerability to noise suggested for low-SR fibers (Lin et al., 2011).

\section{References}

Accili D, Fishburn CS, Drago J, Steiner H, Lachowicz JE, Park BH, Gauda EB, Lee EJ, Cool MH, Sibley DR, Gerfen CR, Westphal H, Fuchs S (1996) A targeted mutation of the D3 dopamine receptor gene is associated with hyperactivity in mice. Proc Natl Acad Sci U S A 93:1945-1949.

Beaulieu JM, Gainetdinov RR (2011) The physiology, signaling, and pharmacology of dopamine receptors. Pharmacol Rev 63:182-217.

d'Aldin C, Puel JL, Leducq R, Crambes O, Eybalin M, Pujol R (1995) Effects of a dopaminergic agonist in the guinea pig cochlea. Hear Res 90:202-211.

Darrow KN, Simons EJ, Dodds L, Liberman MC (2006a) Dopaminergic innervation of the mouse inner ear: evidence for a separate cytochemical group of cochlear efferent fibers. J Comp Neurol 498:403-414.

Darrow KN, Maison SF, Liberman MC (2006b) Cochlear efferent feedback balances interaural sensitivity. Nat Neurosci 9:1474-1476.

Darrow KN, Maison SF, Liberman MC (2007) Selective removal of lateral olivocochlear efferents increases vulnerability to acute acoustic injury. J Neurophysiol 97:1775-1785.

Dau J, Wenthold RJ (1989) Immunocytochemical localization of neurofilament subunits in the spiral ganglion of normal and neomycin-treated guinea pigs. Hear Res 42:253-263.

Drago J, Gerfen CR, Lachowicz JE, Steiner H, Hollon TR, Love PE, Ooi GT, Grinberg A, Lee EJ, Huang SP, Bartlettii PF, Jose PA, Sibley DR, Westphal H (1994) Altered striatal function in a mutant mouse lacking D1A dopamine receptors. Proc Natl Acad Sci U S A 91:12564-12568.

Elgoyhen AB, Vetter DE, Katz E, Rothlin CV, Heinemann SF, Boulter J (2001) alpha10: a determinant of nicotinic cholinergic receptor function in mammalian vestibular and cochlear mechanosensory hair cells. Proc Natl Acad Sci U S A 98:3501-3506.

Eybalin M, Charachon G, Renard N (1993) Dopaminergic lateral efferent innervation of the guinea-pig cochlea: immunoelectron microscopy of catecholamine-synthesizing enzymes and effect of 6-hydroxydopamine. Neuroscience 54:133-142.

Gáborján A, Lendvai B, Vizi ES (1999) Neurochemical evidence of dopamine release by lateral olivocochlear efferents and its presynaptic modulation in guinea-pig cochlea. Neuroscience 90:131-138.

Gao J, Maison SF, Wu X, Hirose K, Jones SM, Bayazitov I, Tian Y, Mittleman G, Matthews DB, Zakharenko SS, Liberman MC, Zuo J (2007) Orphan glutamate receptor deltal subunit required for high-frequency hearing. Mol Cell Biol 27:4500-4512.

Garrett AR, Robertson D, Sellick PM, Mulders WH (2011) The actions of dopamine receptors in the guinea pig cochlea. Audiol Neurootol 16:145-157.

Groff JA, Liberman MC (2003) Modulation of cochlear afferent response by the lateral olivocochlear system: activation via electrical stimulation of the inferior colliculus. J Neurophysiol 90:3178-3200. 
Guinan JJ Jr (2006) Olivocochlear efferents: anatomy, physiology, function, and the measurement of efferent effects in humans. Ear Hear 27:589-607.

Halmos G, Doleviczényi Z, Répássy G, Kittel A, Vizi ES, Lendvai B, Zelles $\mathrm{T}$ (2005) D2 autoreceptor inhibition reveals oxygen-glucose deprivation-induced release of dopamine in guinea-pig cochlea. Neuroscience 132:801-809.

Hequembourg S, Liberman MC (2001) Spiral ligament pathology: a major aspect of age-related cochlear degeneration in C57BL/6J mice. J Assoc Res Otolaryngol 2:118-129.

Holmes A, Hollon TR, Gleason TC, Liu Z, Dreiling J, Sibley DR, Crawley JN (2001) Behavioral characterization of dopamine D5 receptor null mutant mice. Behav Neurosci 115:1129-1144.

Hossain WA, Antic SD, Yang Y, Rasband MN, Morest DK (2005) Where is the spike generator of the cochlear nerve? Voltage-gated sodium channels in the mouse cochlea. J Neurosci 25:6857-6868.

Inoue T, Matsubara A, Maruya S, Yamamoto Y, Namba A, Sasaki A, Shinkawa $\mathrm{H}$ (2006) Localization of dopamine receptor subtypes in the rat spiral ganglion. Neurosci Lett 399:226-229.

Jones N, Fex J, Altschuler RA (1987) Tyrosine hydroxylase immunoreactivity identifies possible catecholaminergic fibers in the organ of Corti. Hear Res 30:33-38.

Karadaghy AA, Lasak JM, Chomchai JS, Khan KM, Drescher MJ, Drescher DG (1997) Quantitative analysis of dopamine receptor messages in the mouse cochlea. Mol Brain Res 44:151-156.

Kelly MA, Rubinstein M, Asa SL, Zhang G, Saez C, Bunzow JR, Allen RG, Hnasko R, Ben-Jonathan N, Grandy DK, Low MJ (1997) Pituitary lactotroph hyperplasia and chronic hyperprolactinemia in dopamine D2 receptor-deficient mice. Neuron 19:103-113.

Kujawa SG, Liberman MC (2009) Adding insult to injury: cochlear nerve degeneration after "temporary" noise-induced hearing loss. J Neurosci 29:14077-14085.

Lendvai B, Halmos GB, Polony G, Kapocsi J, Horváth T, Aller M, Sylvester Vizi E, Zelles T (2011) Chemical neuroprotection in the cochlea: the modulation of dopamine release from lateral olivocochlear efferents. Neurochem Int 59:150-158.

Liberman LD, Wang H, Liberman MC (2011) Opposing gradients of ribbon size and AMPA receptor expression underlie sensitivity differences among cochlear-nerve/hair-cell synapses. J Neurosci 31:801-808.

Liberman MC (1980a) Morphological differences among radial afferent fibers in the cat cochlea: An electron-microscopic study of serial sections. Hear Res 3:45-63.

Liberman MC (1980b) Efferent synapses in the inner hair cell area of the cat cochlea: An electron microscopic study of serial sections. Hear Res 3:189-204.

Liberman MC (1990) Effects of chronic cochlear de-efferentation on auditory-nerve response. Hear Res 49:209-224.

Liberman MC, Mulroy MJ (1982) Acute and chronic effects of acoustic trauma: Cochlear pathology and auditory nerve pathophysiology. In: New perspectives on noise-induced hearing loss (Hamernik RP, Henderson D, Salvi R, eds), pp 105-136. New York: Raven.

Liberman MC, Dodds LW, Pierce S (1990) Afferent and efferent innervation of the cat cochlea: quantitative analysis with light and electron microscopy. J Comp Neurol 301:443-460.

Lin HW, Furman AC, Kujawa SG, Liberman MC (2011) Primary neural degeneration in the Guinea pig cochlea after reversible noise-induced threshold shift. J Assoc Res Otolaryngol 12:605-616.

Maison SF, Luebke AE, Liberman MC, Zuo J (2002) Efferent protection from acoustic injury is mediated via alpha9 nicotinic acetylcholine receptors on outer hair cells. J Neurosci 22:10838-10846.

Maison SF, Adams JC, Liberman MC (2003) Olivocochlear innervation in mouse: immunocytochemical maps, crossed vs. uncrossed contributions and colocalization of ACh, GABA, and CGRP. J Comp Neurol 455:406-416.

Maison SF, Rosahl TW, Homanics GE, Liberman MC (2006) Functional role of GABAergic innervation of the cochlea: phenotypic analysis of mice lacking GABA(A) receptor subunits alpha 1, alpha 2, alpha 5, alpha 6, beta 2, beta 3, or delta. J Neurosci 26:10315-10326.

Maison SF, Vetter DE, Liberman MC (2007) A novel effect of cochlear efferents: in vivo response enhancement does not require alpha9 cholinergic receptors. J Neurophysiol 97:3269-3278.

Maison SF, Liu XP, Vetter DE, Eatock RA, Nathanson NM, Wess J, Liberman
MC (2010) Muscarinic signaling in the cochlea: presynaptic and postsynaptic effects on efferent feedback and afferent excitability. J Neurosci 30:6751-6762.

Matsubara A, Laake JH, Davanger S, Usami S, Ottersen OP (1996) Organization of AMPA receptor subunits at a glutamate synapse: quantitative immunogold analysis of hair cell synapses in the rat organ of Corti. J Neurosci 16:4457-4467.

McLean WJ, Smith KA, Glowatzki E, Pyott SJ (2009) Distribution of the $\mathrm{Na}, \mathrm{K}-\mathrm{ATP} a \mathrm{se}$ alpha subunit in the rat spiral ganglion and organ of corti. J Assoc Res Otolaryngol 10:37-49.

Mulders WH, Robertson D (2004) Dopaminergic olivocochlear neurons originate in the high frequency region of the lateral superior olive of guinea pigs. Hear Res 187:122-130.

Niu X, Canlon B (2002) Activation of tyrosine hydroxylase in the lateral efferent terminals by sound conditioning. Hear Res 174:124-132.

Niu X, Canlon B (2006) The signal transduction pathway for the dopamine D1 receptor in the guinea-pig cochlea. Neuroscience 137:981-990.

Pujol R, Lenoir M, Robertson D, Eybalin M, Johnstone BM (1985) Kainic acid selectively alters auditory dendrites connected with cochlear inner hair cells. Hear Res 18:145-151.

Robertson D (1983) Functional significance of dendritic swelling after loud sounds in the guinea pig cochlea. Hear Res 9:263-278.

Roux I, Safieddine S, Nouvian R, Grati M, Simmler MC, Bahloul A, Perfettini I, Le Gall M, Rostaing P, Hamard G, Triller A, Avan P, Moser T, Petit C (2006) Otoferlin, defective in a human deafness form, is essential for exocytosis at the auditory ribbon synapse. Cell 127:277-289.

Rubinstein M, Phillips TJ, Bunzow JR, Falzone TL, Dziewczapolski G, Zhang G, Fang Y, Larson JL, McDougall JA, Chester JA, Saez C, Pugsley TA, Gershanik O, Low MJ, Grandy DK (1997) Mice lacking dopamine D4 receptors are supersensitive to ethanol, cocaine, and methamphetamine. Cell 90:991-1001.

Ruel J, Nouvian R, Gervais d'Aldin C, Pujol R, Eybalin M, Puel JL (2001) Dopamine inhibition of auditory nerve activity in the adult mammalian cochlea. Eur J Neurosci 14:977-986.

Ruel J, Wang J, Demêmes D, Gobaille S, Puel JL, Rebillard G (2006) Dopamine transporter is essential for the maintenance of spontaneous activity of auditory nerve neurones and their responsiveness to sound stimulation. J Neurochem 97:190-200.

Simmons DD, Moulding HD, Zee D (1996) Olivocochlear innervation of inner and outer hair cells during postnatal maturation: an immunocytochemical study. Brain Res Dev Brain Res 95:213-226.

Stankovic KM, Corfas G (2003) Real-time quantitative RT-PCR for lowabundance transcripts in the inner ear: analysis of neurotrophic factor expression. Hear Res 185:97-108.

Vetter DE, Liberman MC, Mann J, Barhanin J, Boulter J, Brown MC, SaffioteKolman J, Heinemann SF, Elgoyhen AB (1999) Role of alpha9 nicotinic ACh receptor subunits in the development and function of cochlear efferent innervation. Neuron 23:93-103.

Vetter DE, Li C, Zhao L, Contarino A, Liberman MC, Smith GW, Marchuk Y, Koob GF, Heinemann SF, Vale W, Lee KF (2002) Urocortin-deficient mice show hearing impairment and increased anxiety-like behavior. Nat Genet 31:363-369.

Vetter DE, Katz E, Maison SF, Taranda J, Turcan S, Ballestero J, Liberman MC, Elgoyhen AB, Boulter J (2007) The alpha10 nicotinic acetylcholine receptor subunit is required for normal synaptic function and integrity of the olivocochlear system. Proc Natl Acad Sci U S A 104:20594-20599.

Vizi ES, Lábos E (1991) Non-synaptic interactions at presynaptic level. Prog Neurobiol 37:145-163.

Walsh EJ, McGee J, McFadden SL, Liberman MC (1998) Long-term effects of sectioning the olivocochlear bundle in neonatal cats. J Neurosci 18:3859-3869.

Wang Y, Hirose K, Liberman MC (2002) Dynamics of noise-induced cellular injury and repair in the mouse cochlea. J Assoc Res Otolaryngol 3:248-268.

Wiederhold ML, Kiang NY (1970) Effects of electric stimulation of the crossed olivocochlear bundle on single auditory-nerve fibers in the cat. J Acoust Soc Am 48:950-965.

Winter IM, Robertson D, Yates GK (1990) Diversity of characteristic frequency rate-intensity functions in guinea pig auditory nerve fibres. Hear Res 45:191-202. 